This item was submitted to Loughborough's Research Repository by the author.

Items in Figshare are protected by copyright, with all rights reserved, unless otherwise indicated.

\title{
Flexible radio frequency connectors for textile electronics
}

PLEASE CITE THE PUBLISHED VERSION

http://dx.doi.org/10.1049/el.2013.2105

\section{PUBLISHER}

(c) The Institution of Engineering and Technology

VERSION

AM (Accepted Manuscript)

LICENCE

CC BY-NC-ND 4.0

REPOSITORY RECORD

Seager, R.D., Alford Chauraya, Shiyu Zhang, W.G. Whittow, and J.C. Vardaxoglou. 2019. "Flexible Radio Frequency Connectors for Textile Electronics". figshare. https://hdl.handle.net/2134/13522. 
This item was submitted to Loughborough's Institutional Repository (https://dspace.lboro.ac.uk/) by the author and is made available under the following Creative Commons Licence conditions.

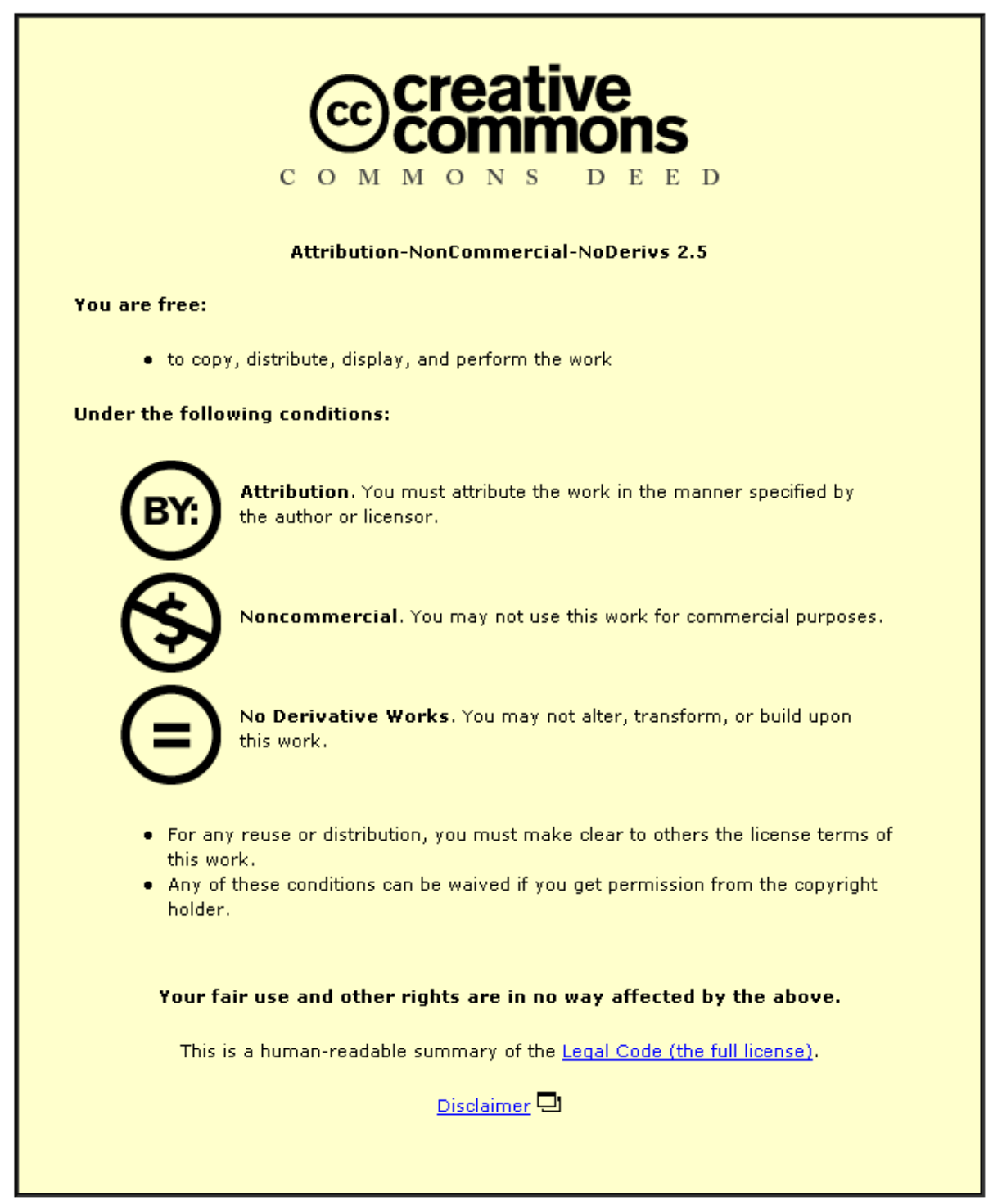

For the full text of this licence, please go to: http://creativecommons.org/licenses/by-nc-nd/2.5/ 


\section{Flexible radio frequency (RF) connectors for textile electronics.}

\author{
R. D. Seager, A. Chauraya, S. Zhang, W. Whittow and Y. \\ Vardaxoglou
}

\begin{abstract}
A new approach to interfacing fabric based wireless systems to traditional electronics circuitry is presented. Measurements show possible insertion losses of the connector to be less than $1 \mathrm{~dB}$ up to frequencies around $4 \mathrm{GHz}$ when electroplating has been used to increase the hook and loop conductivity. The work presented here points towards an interconnection system that is flexible and will allow removal and replacement of conventional electronics connected to textile based systems.
\end{abstract}

Introduction: There is a large body of research publications on fabric based antennas [1-6]. Several authors have also considered textile transmission lines $[7,8]$. The major issue that most authors do not address is the problem of connecting standard electronics circuitry working at microwave frequencies to a fabric sub-system. Use of a conductive yarn such as Amberstrand [9] will allow soldering. In some cases this may well be the optimum solution. This paper presents the use of conductive hook and loop [10] to form a flexible connector that is detachable and reusable. Some authors have addressed the problem of commercial reusable connections for low frequency control signals $[11,12]$. The second of these uses optical signals for the transfer of control signals.

The use of conductive hook and loop connectors for textile wireless systems is presented. Representative measurements have been taken for frequencies between $500 \mathrm{MHz}$ and $6 \mathrm{GHz}$. These indicate that a workable, repeatable connector may be fabricated using this technology. Fig. 1 shows a photo of the test jig used in this work.

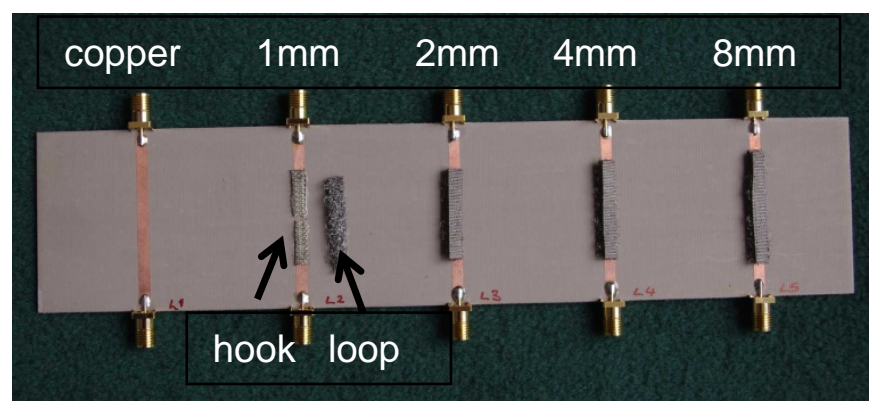

Fig 1. Test jig used for measurements

The test jig contains a copper microstrip line and a series of microstrip lines with different length gaps (1, 2, 4 and $8 \mathrm{~mm})$. The substrate is $1.6 \mathrm{~mm}$ thick FR-45 with a relative permittivity of 4.5 . All the lines are designed to be $50 \Omega$. The use of a rigid substrate is deliberate to allow assessment of the interconnections. On the gapped microstrip lines there is a fixed length of hook (see $1 \mathrm{~mm}$ line) affixed to the microstrip using a conductive epoxy. The loop component is used to bridge the gap. The line with no gap is used as a reference. The measurements presented here, for a 'switch' with two contacts, allow assessment of both the contact between the two component parts and the insertion loss in the loop section of the interconnection. The envisaged connectors can be fixed to transmission lines using conductive yarn in the production process. Electroplating using copper has been used to increase the conductivity of the hook and loop and some improvements can be seen.

Results: Fig. 2 shows measured $\mathrm{S}_{21}$ results for the five lines shown in Fig. 1 for a commercially available hook and loop system available to the electromagnetic compatibility (EMC) community. The continuous line is the transmission measurement of the copper microstrip line as shown to the left in Fig 1. Up to 2GHz the insertion loss (around 2dB) looks acceptable, for the standard hook and loop, given that the number of transitions between the hook and the loop is twice that envisaged in the final application as a connector between traditional electronics and a fabric system.

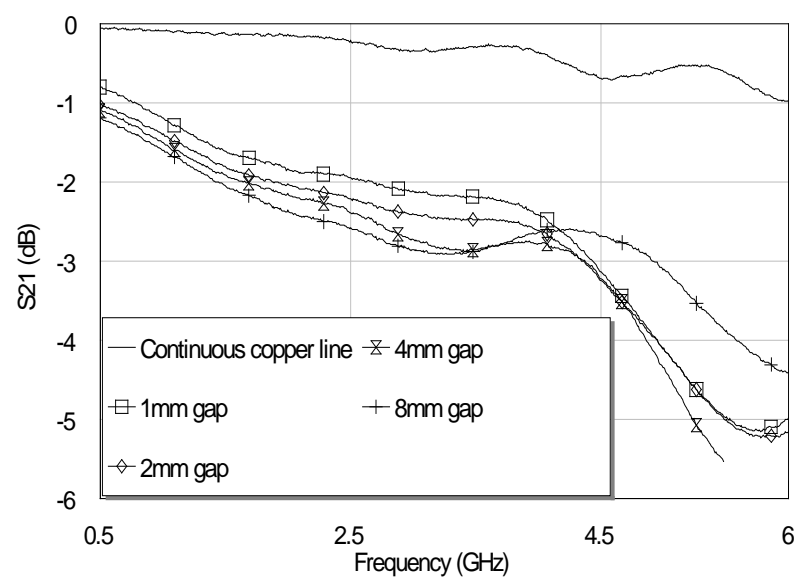

Fig $2 S_{21}$ for hook and loop 'switches'

Fig 3 shows the transmission for the four gapped lines using electroplated hook and loop. Generally, the insertion loss has improved significantly.

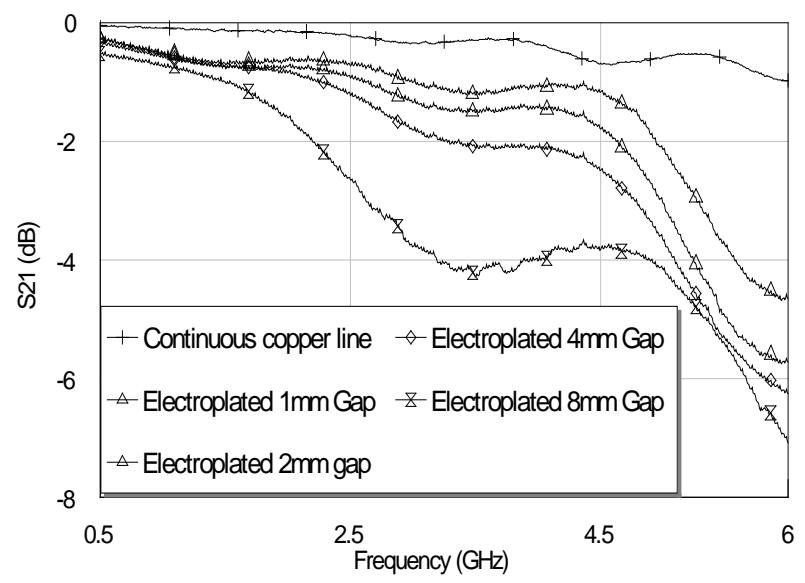

Fig 3. $S_{21}$ for electroplated hook and loop 'switches"

Fig. 4 shows the $\mathrm{S}_{11}$ data for all eight hook and loop 'switches'. In virtually all cases (the $8 \mathrm{~mm}$ line is the exception) a reasonable impedance match is achieved up to the $4 \mathrm{GHz}$ region.

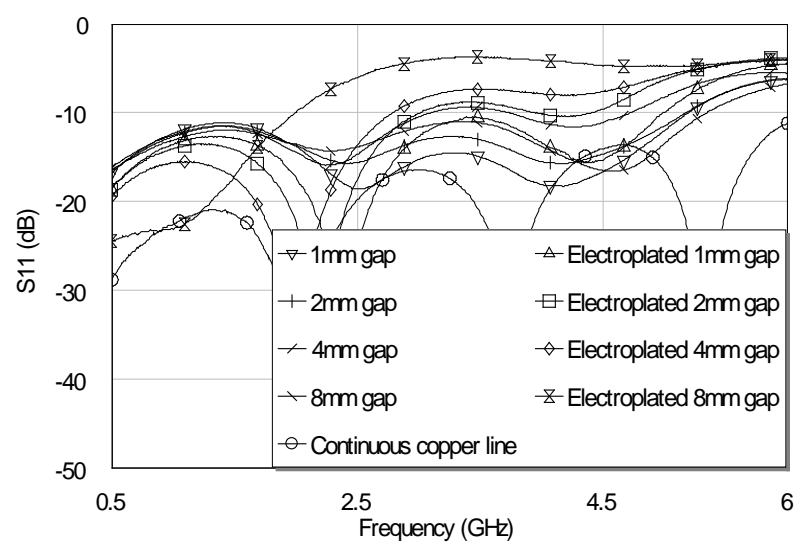

Fig 4. $S_{11}$ data for all eight hook and loop measurements

Fig. 5 shows a direct comparison of the transmission through the two $1 \mathrm{~mm}$ gap hook and loop sections clearly showing how the added conductivity given by the electroplating has improved the RF performance. 


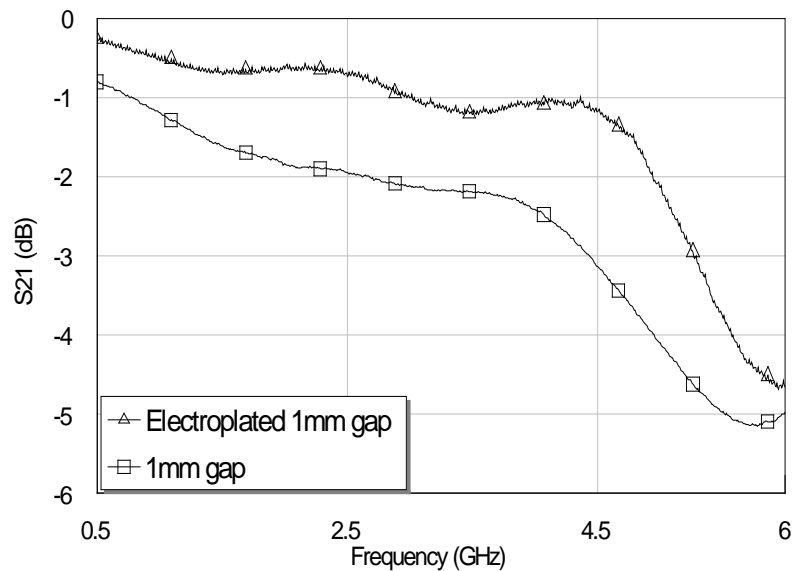

Fig 5. Comparison of transmission for $1 \mathrm{~mm}$ gap hook and loop with, and without, added electroplating

Conclusion: The results presented in this paper clearly show that hook and loop systems can be used as a connector at low microwave frequencies. The 'switch' format used here will give a higher insertion loss than one would expect to find in a connector using hook and loop. The use of electroplating has indicated that higher conductivities will extend the frequency range of the connectors. The electroplating process used here stiffened the loop component. Increasing the conductivity at the manufacturing stage should be able to remove this problem. Electroplating the hook and loop with copper has produced a significantly lower insertion loss of around $1 \mathrm{~dB}$ up to $2 \mathrm{GHz}$, except for the $8 \mathrm{~mm}$ gap, see Fig. 3 . If a $2 \mathrm{~dB}$ Insertion Loss is deemed acceptable then a frequency range in excess of $4 \mathrm{GHz}$ may be considered.

A reusable connector that allows electronics to be removed from a fabric system for security or other reasons, such as washing has been demonstrated. This concept makes is a useful and important addition to textile RF systems. A wider transmission line would work better with the hook and loop connectors proposed. This fits well with textiles where relative permittivities are generally relatively low.

Acknowledgments: This work was supported by the Innovative electronics Manufacturing Centre (IeMRC) research grant "High Performance Flexible, Fabric Electronics for MegaHertz Frequency Communications"

R. D. Seager, A. Chauraya, S. Zhang, W. Whittow and Y. Vardaxoglou are with the School of Electronic, Electrical and Systems Engineering, Loughborough University, Ashby Road, Loughborough, LE11 3TU,

U.K.

E-mail: R.D.Seager@lboro.ac.uk

\section{References}

1. Kim B, Son Y, Jeong H, and Cho. "Velcro Connector", US Patent, Patent No. 7753686 B2, July, 13, 2010.

2. Gupta B, Sankaralingam S and Dhar S. "Development of wearable and implantable antennas in the last decade: A review," in Microwave Symposium (MMS), 2010 Mediterranean, 2010, pp. 251-267.

3. Rais N H M., Soh P J, Malek F, Ahmad S, Hashim N B M and Hall P S. "A Review of Wearable Antenna," in Loughborough Antennas \& Propagation Conference (LAPC), 2009, November, pp. 225-228.

4. Matthews J C G and Pettitt G. "Development of Flexible , Wearable Antennas," in European Conference on Antennas \& Propagation (EuCAP), 2009, pp. 273-277.

5. Lilja J, Salonen P, Kaija T and de Maagt P. "Design and Manufacturing of Robust Textile Antennas for Harsh
Environments," IEEE Transactions on Antennas and Propagation, vol. 60, no. 9, pp. 4130-4140, Sep. 2012

6. Kennedy TF, Fink PW, Chu AW, Champagne, II NJ, Lin GY and Khayat MA.. "Body-Worn ETextile Antennas: The Good, the Low-Mass, and the Conformal," IEEE Transactions on Antennas and Propagation, vol. 57, no. 4, pp. 910-918, April 2009

7. Cottet D, Grzyb J, Kirstein T, \& Troster G. Electrical characterization of textile transmission lines. IEEE Transactions on Advanced Packaging, 26(2), 182-190, (2003). doi:10.1109/TADVP.2003.817329

8. Kirstein T, \& Cottet D. (2002). Textiles for signal transmission in wearables. (Retrieved May 24, 2013, from http://www.wearable.ethz.ch/research/groups/textiles/Conduc tiveTextiles/kirstein02a.pdf)

9. Amberstrand: http://www.metalcladfibers.com/amberstrandfiber/ (Last accessed 18/12/12)

10. Conductive Hook and Loop Fastener. LessEMF.com, Latham, NY, 12110-2209,USA: (http://www.lessemf.com/fabric.html\#207 (Last Accessed $3^{\text {rd }}$ June 2013)

11. Kim B-I, Shin HS, Son Y-K, Cho I-Y, Lee HS. "Interfacing Mobile Devices with Electronic Textiles Using Spatial Information," Wearable Computers (ISWC), 2011 15th Annual International Symposium on , pp.111,112, 12-15 June 2011

12. Lee HS and Cho I-Y. "Drop-n-Play: A New Device Interface for iPod Jackets," in International Conference on Consumer Electronics, Las Vegas, 2010, pp. 183-184. 

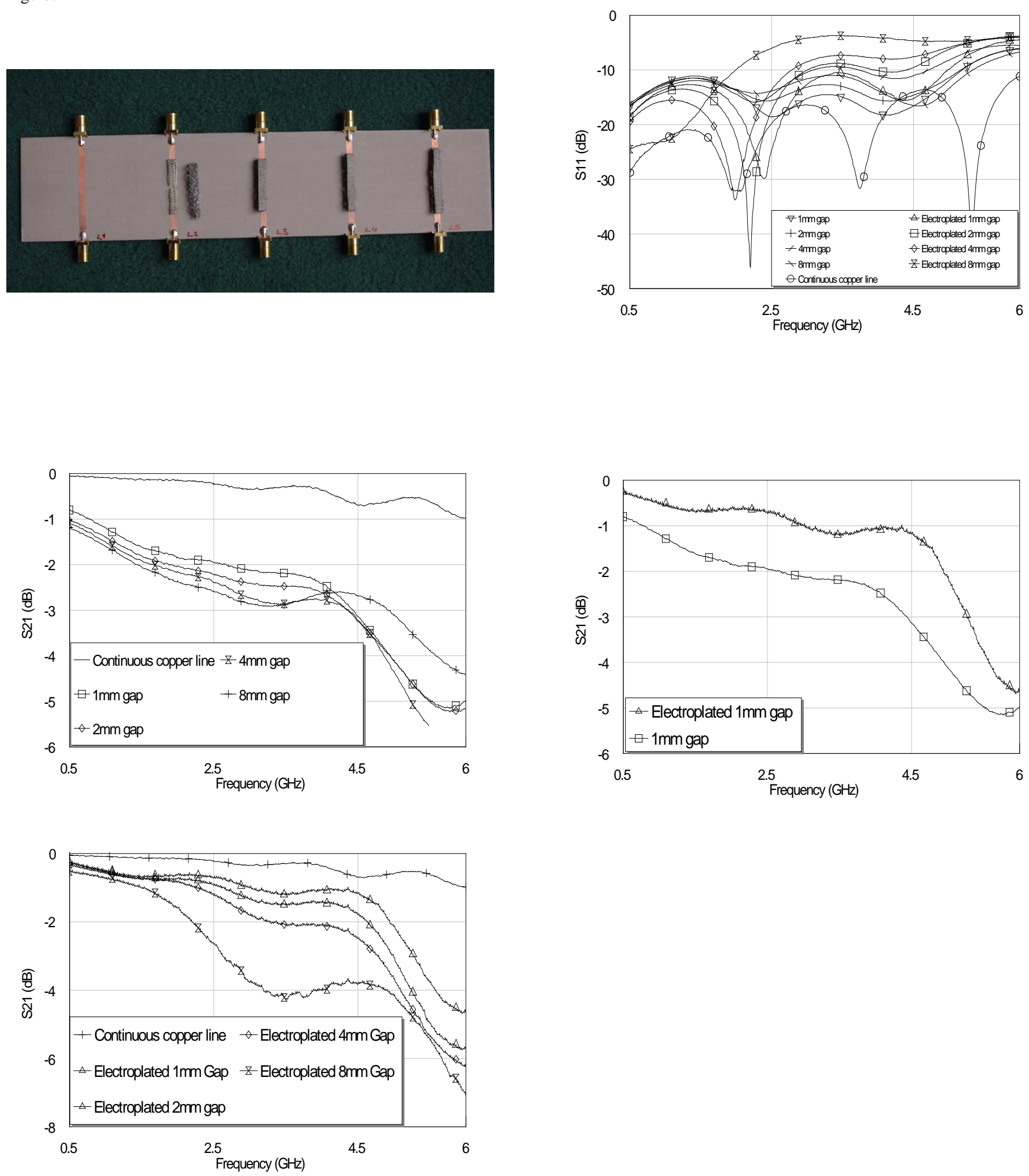